\title{
THE CHALLENGES OF CLASSIFICATION: EMERGING VOIP REGULATION IN EUROPE AND THE UNITED STATES*
}

IE Working Paper

David Bach

Instituto de Empresa Business School

Serrano 105

28006, España

Spain

david.bach@ie.edu
DE8-121-I

$12-04-2005$

Jonathan Sallet

University of California, Berkeley Institute of International Studies

Berkeley, CA 94720 USA

jonathan@sallet.com

\begin{abstract}
:
Internet telephony -or Voice over Internet Protocol (VOIP)- has the pote ntial to transform the world of voice communicati ons more profoundl $y$ than anything since the inv ention of the telephon e itself. As tele communications incumbents and a range of new entrants begin rolling out commercial VOIP services, policymakers around the world are grappling with the regulatory implications. In the United States and the European Uni on, the two largest potential VOIP markets, efforts are under way to fit VOIP into ex isting regulatory frameworks. This process of "re gulatory classification" is b y no means a purely administrative act. A lot is at stake and different interest groups have therefore mobilized to shape the respective outcomes. B ecause legacy regulatory systems in Eur ope and the United States differ, the regulatory treatment of VOIP in the two markets is beginning to differ as well. Yet in both markets there is a substa ntial danger that fitting VOIP into e xisting classifications will force VOIP to look more lik e regular telephony, thereby limiting its innovation potential.
\end{abstract}

* The authors would like to thank Link Hoewing, Carmen Mateas, and Steve Weber for helpful comments and suggestions on earlier drafts of this paper. 



\section{INTRODUCTION}

Over the next decade, telephony is going to change more dramatically than it has over the past one hundred years. The rise of Internet telephony - or what experts call Voice-overInternet-Protocol (VOIP) - represents a watershed in the history of telecommunications. Since the days of Alexander Graham Bell, voice communication has consisted of linking a device designed exclusively for voice communication (called a "telephone") to a network designed to carry voice traffic (called a "telephone network"). VOIP turns voice communications into just another application on the all-purpose data network called the Internet. Software replaces the telephone. Any device equipped with such software - a computer, a personal digital assistant, a sophisticated headset, or just a box that looks like a telephone - that is connected to the broadband Internet can serve as a terminal for voice communications. Turning telephony into a software application enables stunning new services and features, from dramatically enhanced sound quality through global call forwarding to seamless integration with video. Best of all, all of this comes at dramatically reduced cost.

Given these attributes, it does not take an ora cle to predict that V OIP will essentially replace conventional telephony over the next decade or two. In the network backbone, this has already happened. Many operators now route international calls over IP networks, leading to significant savings that have slashed international calling charges to often just a few cen ts a mi nute. VOIP has been similarly successful among high-end business users. Traffic to and from call centers and among the offices of globally operating companies increasingly bypasses conventional telephone networks. With the rapid diffusion of broadband Internet access, VOIP is now beginning to conquer the residential customer market as well. Pioneers such as Vonage in the United States now serve half-a-million customers and virtually all leading operators in Europe and the US are hastily working on their VOIP strategies.

That we are transitioning into a world of VOIP seems clear. How we will get there is not. A principal driving force on the transition path will be regulation. Telecommunications is a tightly regulated industry, partly because of the strategic importance of voice communications for economy and society, partly because of the externalities that characterize network industries, and partly simply because of political legacies. How existing regulation will be applied to VOIP and the content of potential new rules will shape the evolution of technology and markets. Am ong the most pressing regulatory issues are the interoperability of VOIP with existing networks, access to emergency services, network security, wiretapping, numbering, and universal service funding.

All of these issues are no doubt important. But the one that stands out - both with respect to the attention it has received by regulators so far and in terms of its importance for the future of VOIP - is what we ma y loosely call "regulatory classification." From a practical point of view, classification stands out because classifying different services is what regulators principally do. In an ideal world, one could just draw up rules for VOIP that address the aforementioned critical issues, keeping in mind the technology's novelty and the substantial differences that exist between conventional circuit-switched telephony 
and innovative packet-switched VOIP. In the real world, however, a first step in the regulation of new technologies is usually to try to fit them into existing service categories, in part because those are the tools that regulators work with and in part because classification can provide shortcuts through complex regulatory problems. Much is therefore at stake in these decisions.

Fitting VOIP into existing regulatory categories is not simply an admi nistrative or technical act. Si nce categories are associated with distinct sets of rights and responsibilities that have distributional and market strategic implications, a large number of stakeholders have mobilized to affect the outcome. We thus inevitably enter the realm of politics. Here we mean "politics" with a small "p", that is, the complex back and forth among powerful interests that overshadows what are nominally purely administrative processes. Parliaments and elected governments have so far barely entered the frail. But this does not mean that the process is not political.

Unpacking the political economic dynamics of evolving VOIP regulation highlights a second, more analytic reason to focus on classification. The debate over how to classify VOIP represents the leading edge of the question whether regulatory classification is useful in a world of converging technologies. In other words, precisely because VOIP forces the convergence of previous era telecommunications and the Internet, we ought to pause and ask whether regulation from that previous era still makes sense.

This article then has three main objectives. In the first part, we show why VOIP will be regulated, sketch issues that require regulatory attention, and elaborate why most attention is currently focused on classifying VOIP services based on existing regulatory frameworks. In the second part, we explain the distinct regulatory systems in the European Union and the United States, and analyze efforts to date to treat VOIP under these systems. In both markets, politics and interest diversions among stakeholder camps dominate the process. Yet because of different regulatory systems and industry structures, regulatory responses that begin from distinct perspectives are struggling with similar challenges. In the third part we then open the debate up and analyze more closely the political issues that run through the narrow technical debates over classification. Regulators are vying for influence and are fighting over the allocation of regulatory authority. Incumbents in the United States and Europe are adopting different strategies towards this new technology. New entrants are fighting for market rules that allow them to take on the incumbents. Meanwhile policymakers are struggling to maintain a system that solves many political problems, re gardless of the negative effects it may have on evolving markets and technologies. The article concludes with some critical reflections. VOIP has tremendous innovation potential and will transform the way we communicate. It provides vast opportunities for new services that will create real value for consumers. Policymakers should thus contemplate harnessing the transformative potential of VOIP to drive a modernization of telecommunications regulation as well. Were that to happen, VOIP would indeed signal a new era on all fronts. 


\section{THE RAPID RISE AND INEVITABLE REGULATION OF VOIP}

VOIP has been phenomenally successful in just a few years. At the end of 2003, residential VOIP in the United States basically did not exist. By the end of 2004, 400.000 American households had signed up for VOIP services. I ndustry observers forecast 12.1 million US h ouseholds to use VOIP within just five years. ${ }^{1}$ These optimistic projections are backed up by spectacular growth over the last two years in Japan. There, ten percent of households use VOIP to make calls just two years after such services were introduced. ${ }^{2}$ Voice service has quickly become a standard feature of broadband packages. More than 90 percent of Yahoo BB's three million broadband subscribers in Japan, for example, have also signed up for VOIP. Last year's auction of roughly nine million VOIP telephone numbers indicates where policymakers believe the industry is headed. ${ }^{3}$ Europe, finally, has been the region of the world with the fastest growth of VOIP minutes over the past year, though much of this comes from high-end business users. $^{4}$

One driver of this success is greater efficiency. Rath er than wastefully dedicating an entire circuit to a single voice communication, VOIP divides up the audio signal in packets and routes them over the all-purpose Internet. Yet efficiency alone is only part of the story. Whereas ordinary circuit-switched telephony is capped at $64 \mathrm{kbps}$ by network design, VOIP can support communication with higher bandwidth. This allows for much better voice quality and the bundling with other applications such as simultaneous text or video messaging. Business users in particular will find the ability to seamlessly integrate voice communications into Internet-enabled productivity and distance collaboration applications enticing.

A second cluster of VOIP advantages centers on mobility, or what experts are calling "nomadic" applications. Just as one can check personal e-mail and surf the web from just about anywhere in the wo rld, a user could receive VOIP calls to a single number anywhere she is connected to the broadband Internet, whether wired or wireless. Think of it as a universal, provider and technology-independent global roaming service. These nomadic dimensions will enable a whole range of new services, particularly when combined with $t$ echnologies such as ENUM that permit the bundling of diverse communications services like fixed telephony, wireless telephony, fax, e-mail, and instant messaging under a single identifier. ${ }^{5}$

Exciting as these new efficiency, quality, and service aspects may be, the transformative power of VOIP stems principally from its inversion of the previous logic underpinning telecommunications network design. The old, circuit-switched world is network centric. Any new service - such as call w aiting, call forwarding, or three-way calling in recent memory - requires complex network reengineering. This architectur al limitation is one

\footnotetext{
${ }^{1}$ Kerner, 2004.

2 "Japan's VOIP Experience Could Preview Things To Come In America," 2003.

${ }^{3}$ Clark, 2004.

${ }^{4}$ Le Maestre, 2003.

${ }^{5}$ For an introduction to ENUM, see ENUM.org.
} 
reason for the low level of innovation in telephony over the past century. The new, packet-switched world, in contrast, is application- or user-centric. New applications and services can be implemented through software, predominantly on the user side, and network reengineering becomes the exception, rather than the rule. ${ }^{6}$ This is a world of user-driven innovation and rapid change. ${ }^{7}$ In short, not so much the currently envisioned services and applications made possible by VOIP are the source of excitement, but rather the fact that a VOIP architecture will support countless services yet to be imagined.

This paradigm shift is too big and too important for anybody in the industry to ignore. Indeed, both new entrants and incumbents have mobilized considerable resources to get onto the VOIP train. In the US, aggressive new entrants such as Vonage have received most of the attention. But leading local incumbents such as BellSouth, SBC, Qwest, and Verizon are p reparing their own VOIP strategies. The picture is similar in Europe, though there has so far not been a powerful new entrant that would shake up the industry as much as Vonage has done in the US. Among Europe's incumbents, British Telecom has been the most ambitious, pledging to move to an all-IP network in the UK by 2009 . France Telecom's Wanadoo and TeliaSonera of Finland and Sweden are some of the other early movers. In addition, a range of new entrants, including Vonage, Lingo, Indigo Networks, and VozTelecom have begun to target business users or have plans to offer residential VOIP service. Vonage, lastly, has begun entering the European market, initially targeting the UK.

What we have then is a sit uation where companies from both worlds - circuit-switched telecommunications and the packet-switched Internet - pursue the new opportunities created by the convergence of underlying technologies and the rise of packet-switched voice services. Most experts are fairly confident that circuit-switching will be a thing of the past before long. Yet how we will get there, who rides the transformative wave most successfully, and who gets stranded in the process, is far from clear.

Regulation will play a crucial role in this transitio $\mathrm{n}$. Law and policy set critical ground rules that structure market competition. This is true in all industries. In the case of VOIP, however, regulation assumes an even more important role. Precisely because it is an instance of converging technologies in which companies from previously distinct industries compete against one another, the content and underlying logic of regulation has the potential to critically affect who wins and who loses in the marketplace. How should rules that were designed for a world of circuit-switched voice telephony apply to a world where voice communication is just another application on the all-purpose Internet? This is not just a question of law and jurisprudence. It is very much a political question and the answer to it will undoubtedly leave a big footprint on VOIP markets and the industry as a whole.

\footnotetext{
${ }^{6}$ David Isenberg has beautifully captured the contrast between these two paradigms and its implications for innovation. See Isenberg, 1997.

${ }^{7}$ For the notion of user-driven innovation, see Bar, 2001, 27-50, and Cohen, DeLong and Zysman, 2000.
} 


\section{Why regulation is inevitable....and difficult!}

There is a fundamental difference between VOIP and previous IP-powered innovations such as e-mail or Instant Messaging: these latter technologies burst into a n ew, unregulated space. There was no market for e-mail prior to the commercial diffusion of e-mail, for instance. There were also no market rules, no incumbents used to operating under these rules, and no past policy objectives dependent on the execution of the rules. Most VOIP services, in contrast, will fall squ arely into the highly regulated space of voice communications. ${ }^{8}$ Over the course of more than a century, policymakers have devised a dense set of rules and regulations covering emergency services, network integrity, universal access, and the allocation of scarce identifiers such as telephone numbers, to name just a f ew. As VOIP displaces current telecommunications technologies, it will inevitably be confronted with these regulatory legacies.

Not only is a regulatory vacuum for VOIP unlikely, it is also not in the interests of market players, including new entrants. $T$ he last mile to th e customer and network interconnection points between the Internet and customers, especially residential customers, are the critical infrastructure for VOIP delivery. VOIP providers need access to broadband lines, which makes a co mpetition-focused application of open access policies paramount. ${ }^{9}$ Likewise, interconnection requirements must ensure that VOIP providers can offer their customers access to any telephone user, whether VOIP or conventional. Telephone numbers are a third resource that new VOIP providers need unfettered access to in order to compete with incumbents on a level-playing field. As long as regulatory uncertainty regarding these and other issues prevails, investments in the new technology and new services will remain low and the benefits of competition and innovation cannot be reaped to the fullest possible extent.

That regulation of VOIP is inev itable, however, does not mean it is e asy. VOIP is confronted by a whole range of regulatory legacies from the previous era. While many still make sense $-p$ articularly in a hybrid world where technologies and market players from both w orlds will compete and coexist - others may have run their course. Regulators on both sides of the Atlantic are currently busy sorting through a complex web of regulatory issues created by the clash of old and new. Among the most critical issues that have to be addressed are:

- Access to emergency services such as 911 .

- Standards for network reliability and security.

- Network interoperability and interconnectivity.

- Provision and funding of universal service.

\footnotetext{
${ }^{8}$ A potential exception are computer-to-computer VOIP systems such as Skype that never touch existing circuit-switched networks. A s Skype moves toward offering connectivity with non-Skype ordinary telephony users, however, that situation may change.

${ }^{9}$ On network openness and competition, see Sallet, 2003. O n March 3, 2005, the US Federal Communication Commission adopted a consent decree that concluded an investigation into whether a small telephone company had blocked its customers' ability to use VOIP services. The company agreed to pay a small fine and that it "shall not block ports used for VOIP applications or otherwise prevent customers from using VOIP applications." See http://hraunfoss.fcc.gov/edocs_public/attachmatch/DA-05-543A1.pdf, accessed 8 April 2005.
} 
- Wiretapping access for law enforcement.

- Allocation of numbers and other identifiers.

However, rather than considering each of these issues in iso lation, regulators from Washington to Brussels have focused most of their attention on regulatory classification. From a regulator's perspective, this makes sense. Deciding from scratch each time a new technology or service comes around which provisions of the law apply and how they should be implemented is tedious and, more importantly, opens the door to arbitrariness and inconsistencies. So if you ask a regulator whether provision "P" applies to a service "S", she will probably respond that it depends if " $S$ " is a service of type "A", "B" or "C", for only services of type "A" have to co mply with provision "P". The same is now happening in the case of VOIP. Rather than arbitrarily deciding which provisions of existing regulation should apply to VOIP and how they should be implemented, regulators are trying to determine what kind of an animal VOIP is and where it falls in the context of existing frameworks. From a regulatory point of view, once there is an objective set of criteria to distinguish different kinds of VOIP services, and to compare and contrast legacy and new services, settling a whole range of regulatory issues becomes simple. The name-of-the-game of evolving VOIP regulation, in othe $r$ words, is classification.

\section{Classifying VOIP IN THE US: CIRCUIT-SWITCHED POLICIES MEET IP}

IP networks are now fully capable of carrying voice communications. That includes playing a role in traditio nal telephone-to-telephone connections (typically in the "longdistance" network), through the use of internet applications, like Vonage, over cable and wireless networks and, perhaps most importantly, as supplied by the owners of traditional circuit-switched networks, including BellSouth, SBC, Qwest and Verizon. So in the United States the technology is ready. Is the world of regulation?

Application of re gulatory-classification categories requires, first, an understanding of who is entitled to do the classifying. On November 9, 2004, the Federal Communications Commission (FCC) took a big step toward answering this question when it pre-empted the ability of the state of Minnesota to apply its traditional telephone-utility regulation to Vonage's IP-telephony service. In its Vonage Order, the FCC ruled that Vonage's DigitalVoice service, as well as similar services such as those offered by cable companies, could be regulated only at the federal level because those services were not, and could not be, limited to the geography of a single state. ${ }^{10}$ The FCC reaso ned that VOIP service

\footnotetext{
${ }^{10}$ In the Matter of Vonage Holdings Corp., No. 03-211 (November 12, 2004)(hereinafter VOIP Order). The controversy arose when the Minnesota Department of Commerce filed a complaint alleging that Vonage was offering telephone services in Minnesota without first obtaining a "cer tificate" to provide those services, that it had not followed state procedure for the provision of emergency 911 services and that it had not filed its price list, as telephone companies are required to do. Thereafter, the Minnesota Public Utilities Commission (PUC) ruled that Vonage was required to comply with its rules and statutes governing telephone carriers. Relying on the definition of "information services" discussed below, Vonage claimed not to be providing a "telephone service" within the meaning of state law. Rejecting the Vonage view, the PUC concluded that Vonage's service was "functionally no different than any other telephone service",
} 
could not be classified as on ly "intrastate" because, given the technological characteristics of a m ovable, packet-based service, Vonage's offering "cannot be separated into interstate and intrastate communications."

\section{Establishing federal jurisdiction and creating some initial benchmarks}

The FCC left itself with a lot of work to do because it now has the obligation to fashion an entire federal law of VOIP. Must VOIP providers contribute to the universal-service funds that provide subsidies to rural and low-income customers? Do VOIP providers have any obligation to exchange traffic with other voice providers and, if so, under what financial terms? Must VOIP providers ensure any level of network or p erformance reliability? Must VOIP providers provide any kind of 911 access and, if not, what sort of notice must be given to customers? Must VOIP providers collect taxes or fees on the services they provide and, if so, which ones? These are only some of the question that, in the US context, turn on the regulatory classification into which VOIP services are placed. $^{11}$

One place to start in answering these questions is to understand how VOIP service fits into the established set of regulatory classifications. In the Un ited States, the most important classification separates "information services" from "telecommunications services." The importance of this distinction comes from the fact that, under US law, an "information service" is presumptively free from regulation while a "telecommunications service" is putatively subject to old-line common carrier requirements. ${ }^{12}$

Two recent FCC $\mathrm{r}$ ulings have created initial benchmarks for the application of this classification scheme to different types of VOIP services. In In the Matter of pulver.com, the FCC concluded in February 2004 that this company's Free World Dialup (FWD) application was an unregulated "information service" subject to the FCC's jurisdiction. In In the Matter of AT\&T, the FCC ruled in April 2004 that "phone-to-phone" services are "telecommunications services" and, thus, subject to the interstate access charge regime applied to long-distance services generally, even if the comm unications are transmitted by means of IP-protocols for some portion of their transmission.

noting specifically that Vonage customers use an "ordinary touchtone phone," that Vonage service was "functionally identical" to other telephone services and that the Vonage service "intersects with the public switched telephone network". VOIP Order, at $2 \&$ nn. 3, 93, \& 113. Shortly thereafter, a federal court barred the PUC Order from taking effect pending judicial review on the grounds that Vonage was offering an "information service" beyond the power of states to regulate and Vonage sought an FCC Order ruling that federal policy pre-empted such state regulation.

${ }^{11}$ In a press conference following the announcement of the FCC action, the Chief of the FCC's Wireline Competition Bureau noted the pending status of a s eries of VOIP proceedings concerning issues that include access charges, law-enforcement requirements and universal service. See http://www.mofo.com/news/print.cfm?MCatID=\&concentrationID=\&ID=1371, accessed 7 October 2004.

${ }^{12}$ Beyond the scope of this paper is the FCC doctrine of "forbearance" by which the regulatory authority can, in specified circumstances, determine that regulatory burdens need not apply even though the jurisdictional basis for their application is present. For example, it would be possible for the FCC to find that a service is a "tel ecommunications service" and then "forbear" from the application of the normal regulatory requirements that accompany that status. 
For practical reasons, the FCC could have scarcely ruled differently way in either case. The pulver decision involved an Internet application that facilitated the broadband transmission of data between two end-users without ever touching the traditional, circuitswitched telephone network. The FCC emphasized, for example, that pulver's servers offer services that are beyond the traditional reach of telephone networks, including information about other members' on-line presence. Yet the agency kept open a door to exercise some authority. Alt hough it co ncluded that the service was no $t$ a "telecommunications service" subject to the t raditional heavy hand of traditional regulation, it was careful to find that the service was an "information service" over which it could, in the future, exercise jurisdiction.

To have concluded that FWD was a telecommunications service would have raised the specter of old-style regulatory provisions applying to a host of Internet applications. Indeed, had the pulver ruling gone the other way, the FCC's ruling that cable modem services do not include the offering of telecommunications services would have been difficult to justify, ${ }^{13}$ as would be its conclusion that "DSL-based internet access service" is also an "information service." FWD service had little impact on the fl ow of traditional telecommunications revenues and subsidies. The servi ce was more of a ho bbyist's plaything than a substitute for the "normal" form of circuit-switched voice calling.

The same could not be said of the AT\&T service, which is why the FCC had to come out the other way. The AT\&T Order concerned a fairly obvious attempt to a void access charges though the simple expedient of touching an IP network. In essence, AT\&T would take a normal call originated on the circuit-switched network, move it temporarily to an IP packet-switched network and then convert it back to a circuit-switched call for the purpose of delivering it for termination on a local telephone network. To the callers, there was nothing about the call that seemed different from traditional circuit-switched telephony.

\footnotetext{
${ }^{13}$ In its Brand X Order, the FCC ruled in 2002 that cable modem service was an "information service" but not a telecommunications service. (Declaratory Ruling of 15 March 2002). On review, an appellate court rejected that assertion, relying on earlier judicial authority that cable modem service included both "information services" (such as surfing the Web) and "telecommunications services" (namely the underlying transmission pathway to the Web). The United States Supreme Court is reviewing that decision and is expected to decide by the end of its current Term. The core issue seems to be whether the cable modem service is "offering" "telecommunications services" when it sells one, integrated, suite of services. One appellate court judge justified the application of telecommunications regulation by asserting that "Internet access involves two separate services; an information service that provides e-mail, web browsing, and other means of manipulating information, and a telecommunications 'pipeline' that transmits the actual data." Brand X Internet Services, v. FCC,$\left(9^{\text {th }}\right.$ Cir. 2003)(Thomas, J., concurring). By contrast, the United States government argues that "cable modem service does not involve distinct information and telecommunications services" as it asserts the Act requires in order for telecommunications regulation to apply. Brief for the Federal Petitioners, at 19. The outcome of this case has enormous implications for continued relevance of these regulatory classifications.

${ }^{14}$ See Appropriate Framework for Broadband Access to the Internet Over Wireline Facilities; Universal Service Obligations of Broadband Providers, CC Docket No. 02-33, Notice of Proposed Rulemaking 5-6 (released 15 February 2002) ("Wireline Broadband NPRM").
} 
Indeed, that was the point of AT\&T's gambit. It was arbitrarily applying regulatory classifications, hoping, by the conversion of a transmission from analog to IP, to a void the requirement of paying local companies the cost of interstate access calls. There were good business reasons for AT\&T to seek this outcome - interstate access charges are more expensive than other forms of delivering traffic for termination on local telephone systems - but the FCC could not countenance the implications of a ruling for AT\&T, including the collapse of the current access-charge regime by carriers quickly following AT\&T's example.

To get to these emin ently sensible conclusions, however, was not a simple legal matter. In particular, the FCC's conclusion that FWD does not constitute a "telecommunications service" could be challenged. The Telecommunications Act of 1996 classifies as a "telecommunications service" "the transmission, between or among points specified by the user, of information of the user's choosing, without change in the form or content of the information as sent and received." The FCC relied on the fact that pulver offers some services that - in traditional US terms - are enh anced beyond simple voice communication, such as the directory service noted above. But, of course, it could be argued to the contrary that the actual exchange of information between end-users was without any "change in the form or con tent of the information" because a voice communication "entered" at one end emerges in (hopefully) identical form at the other.

\section{Classifications form a different era}

One need not reject the FCC analysis, of course, to recognize that the fundamental problem faced by the FCC - which it is in no position to change - is that the definitions of "telecommunications" and "information" services were devised to deal with very different market circumstances. Both terms derive from the distinction between "basic" and "enhanced" services created by the FCC in its famous Computer Inquiry line of decisions in the 1960's and 1970's before the break-up of AT\&T.

Indeed, that's the critical point. Faced wit $h$ the traditional an ti-trust concern that the AT\&T monopoly might impede competition in the separate, competitive market for data services, the FCC fo rmulated definitions whose principal purpose was to constrain a regulated monopoly. Th us, the FCC wanted to ensure that the telecommunications networks were available as an "open" platform for the provision of competitive "enhanced" services and, through requirements of structural separation, that Bell companies could not leverage their telecommunications networks into unfair competitive advantage. Even when the definitions of "enhanced" and "basic" transmogrified into the statutory definitions of "telecommunications" and "information" services in the 1996, the dominant concern was that local bottlenecks not be used as the basis of unfair competition in competitive markets.

That justification is not the basis for current actions. There is no public-policy objection to the widest proliferation of IP-telephony by whoever wishes to deploy it. This means that the d efinitions of "telecommunications" and "information" services, much like horse-drawn buggies fitted with propellers, are being employed for purposes for which they were simply not designed. And that is wh y the FCC's decision in pulver can be 
questioned as a matter of law even though it is clearly correct as a matter of technology, common sense, and public policy.

\section{The big issue remains}

But whether pulver and AT\&T were rightly decided is almost beside the point. The hard question of re gulatory classification remains to be decided. Indeed, perhaps the most notable aspect of the Vonage Order, in which the FCC affirmed federal, but not state, jurisdiction over VOIP, is what the FCC did not decide. It concluded its discussion of jurisdiction without confronting the obvious substantive question of whether the service involved in that case was an "information service" itself. In other words, the FCC has conspicuously avoided addressing the heart of the matter: how to classify a service that uses IP-protocols to allow an end-user to use a device that looks like a telephone to institute a "voice" transmission that sounds the same at the end of the transmission as it did when spoken and is received by another end-user who is either on a telephone or is using a device that, in common parlance, is a "telephone."

Rather than deciding the question, the FCC, in its pe nding rulemaking has simply suggested a list of "functional and economic factors" to be considered in applying the definition of telecommunications and information services. Those factors include:

- Functional equivalence to traditional telephony;

- Substitutability;

- Interconnection with the Public Switched Telephone Network (PSTN) and use of the North American Numbering Plan:

- Peer-to-Peer Communications vs. Network Services;

- Facility Layer vs. Protocol Layers vs. Application Layer. ${ }^{15}$

But this list demonstrates the problem much more than it suggests a solution. If these are the critical issues to be considered, what do they imply for the regulatory treatment of actual VOIP services? The FCC h as asserted jurisdiction over VOIP services without confronting the most basic implication of its regulatory power - how to treat VOIP under current law. ${ }^{16}$ It has confronted the edges of the classification issue without deciding the core principles under which VOIP is provided. Why? As we discuss below, the very inadequacies of network-centric regulatory principles are im peding the ability to base new policy on the realiti es of emerging technologies. Politics, as we are using the term, is thus forcing intelligent policymaking into the shadows, leaving the FCC to act in a way that seems ad hoc and, potentially, arbitrary.

\footnotetext{
${ }^{15}$ NPRM FCC 04-28 (pp. 25-27).

${ }^{16}$ And, as noted in footnote 11 , the FCC has entered into a consent decree that prohibits a small telephone company from blocking its customers' access to VOIP services.
} 


\section{CLASSIFYING VOIP IN EUROPE: THE FIRST TEST FOR A NEW FRAMEWORK}

In sharp contrast to the United States, Europe has recently modernized its telecommunications regulation with a deliberate focus on the implications of the Internet revolution. The principal aim of the 2002 reforms was to induce more competition in a market still characterized by the legacies of almost a century of government monopolies. These government monopolies - which simultaneously served as teleco $\mathrm{m}$ regulators were not broken up by the courts, as in the US. Instead, competition was introduced gradually based on a neg otiated framework. Liberalization began in parts of Europe in the 1980s but really only picked up steam in the 1990s when EU members committed to the separation of regulation from operation, the privatization of state-owned monopolies, and the gradual introduction of competition. ${ }^{17}$ Wireless bec ame the first "test bed" for liberalization and the spectacular success of Europe's GSM, in turn, provided further steam to the liberalization train. ${ }^{18}$

Europe's success in wireless, the challenges posed by the looming broadband Internet revolution, and the rather sluggish introduction of competition in fix ed-line telephony markets provided the justification for polic ymakers to revisit the issue of telecommunications regulation. Whereas the US Telecommunications Act of 1996 had consciously maintained and affirmed the increasingly outdated categories of "information services" and "telecommunications services", the European Commission embarked on an ambitious mission to create a uniform, technology-neutral regulatory framework for electronic communications services. Because many former telecom monopolists had also owned their country's cable networks, artificially distinguishing between these two legacy technologies at the time when digital advances drove convergence made little sense. As a result, fixed-line telephony, cable, and wireless networks now fall under a single regulatory framework.

\section{Making Regulation Technology Neutral}

Adopted in 2002, the new regulatory framework for electronic communications came into force the year after. ${ }^{19}$ The framework's explicit objective is to provide coherent regulation for all transmission networks and services, regardless of underlying technology. In addition to fostering competition, the principal aims of the framework are to promote European market integration and to promote consumer interests. It permits companies to provide new electronic communications services based on a general authorization. No sp ecific administrative authorization by a National Regulatory Authority (NRA) - the equivalent of the FCC in each EU member state - is necessary. It also establishes a right to negotiate interconnection agreements to existing networks. Most importantly for the case of VOIP, the framework defines three distinct types of communications services, each with its own set of rights and obligations:

\footnotetext{
${ }^{17}$ See Thatcher, 1997 and Thatcher, 1999.

${ }^{18} \mathrm{On}$ GSM and its role in driving European telecom liberalization, see Bach, 2000.

19 The framework consists of a Framework Directive (2002/21/EC), the Autorisation Directive (2002/20/EC), the Access Directive (2002/19/EC), the Universal Service Directive (2002/22/EC), and the Privacy Directive (2002/58/EC). Additional provisions that apply are contained in the Competition Directive (2002/77/EC), which was passed the same year.
} 
- Electronic Communications Service (ECS) providers offer services for numeration that consist of the conveyance of signals over electronic communications networks. ECS providers have the right to offer their servic es anywhere in the EU, can obtain numbers, may negotiate interconnection agreements, and can request permission to install facilities on public property. In return, they must meet a variety of obligations. They must inform NRAs of their service offering, publish quality-of-service information, grant subscribers access to directory services, take steps to ensure network security, and safeguard the privacy of consumers.

- Publicly Available Telecommunications Service (PATS) providers offer telephone service for $\mathrm{n}$ ational and international calls to the general public, originate and terminate calls based on a national numbering plan, and provide access to emergency services. PATS providers enjoy all the rights and obligations of ECS providers. In addition, however, they must gua rantee access to emergency services, permit number portability, and ensure network access at fix ed locations in case of $c$ atastrophic network collapse. In exchange, they have the right to access carrier selection and pre-selection functions on networks with substantial market power, port numbers from other providers, and obtain telephone directory listings for their subscribers.

- Universal Service Obligation (USO) is fulfilled by at least one operator per jurisdiction and includ es the provision of a minimu $\mathrm{m}$ quality service at an affordable price. Any ECS or PATS can apply to become the USO provider for a given jurisdiction. Re gulators can require all ECS or PATS to contribute to universal service funding, though they have the right to free providers with small market shares from such obligations.

The three categories are at the heart of European telecommunications regulation. Distinct rights and obligations are associated with each category, regardless of the underlying network technology. Onl y PATS providers, for example, have to guarantee access to emergency numbers. They also have to me et higher quality-of-service standards. In return, however, they have certain privileges that ECS providers do not enjoy. Precisely because assigning VOIP services to a particular regulatory category addresses questions about the rights and responsibilities of VOIP providers, the VOIP debate in Europe has centered on classification. The most important initiative to date in this respect is a consultation by the European Commission.

\section{The European Commission wants to leave a choice...}

Europe does not have a single regulator for telecommunications; there is no "Euro-FCC". Regulatory authority is instead vested in the member states and exercised by the NRAs. ${ }^{20}$ As guardian of EU legislation, a central role in the regulation of VOIP nevertheless falls to the European Commission. To preempt uncoordinated member state policymaking,

${ }^{20}$ Thatcher, 2002. 
the Commission has launched a public consultation to determine how the EU's regulatory framework applies to VOIP.

Consistent with the F CC's pulver decision, the European Commission explicitly notes that computer-to-computer voice communication that never touches the existing circuitswitched PSTN does not fall under the regulatory framework. Services such as Skype, for example, that rely on PCs as access terminals and therefore do not offer a full substitute for voice telephony are viewed as an "information society service" and are freed from conventional telecommunications regulation. Only VOIP offerings that qualify as "communications services" fall under the EU framework. ${ }^{21}$

The critical question is whether VOIP providers that do seek to terminate calls over the existing PSTN - and are thus providers of "communications services" should fall under either the existing ECS or PATS rules, or whether entirely new regulatory categories are necessary. Stressing that VOIP is a dynamic and evolving field with considerable business model experimentation, the Commission "does not propose any formal, rigid classification of $d$ ifferent publicly available VOIP service offerings." ${ }^{22}$ Instead, the cornerstone of the current proposal is to leave it up to individual VOIP providers to opt for regulation under either the existing ECS or PAT S regime. ${ }^{23}$ Each category comes with specific rights and obligations and the providers, argues the Commission, should decide for themselves how to solve the inherent trade-offs.

As ECS, VOIP providers would have to meet fewer regulatory obligations. Und er current regulation, they need not ensure access to emergency numbers, for example. While the Commission notes that NRAs could technically oblige even non-PATS providers to ensure emergency access, it views such an obligation as disproportionate in light of current technical difficulties. Instead, it advocates that NRAs demand VOIP providers that opt for ECS treatment to inform consumers exactly how they handle the issue of emergency calls, if access is available, and if such calls are routed to the nearest emergency center based on location information.

As far as wiretapping, data retention, and other demands of law enforcement are concerned, the regulatory framework contains the same obligations for ECS and PATS. There is a difference with respect to network security, however. Again, the responsibility of ECS is lighter. While the Commission highlights that EC S-opting VOIP providers would have to take steps against viruses or denial-of-service attacks, the obligations of PATS are considerably greater. Again, the Commission appears content with adequate information of con sumers of the security limitations of new VO IP service, both on the network level and with respect to the vulnerability of terminals to power failures.

\footnotetext{
${ }^{21}$ The term "information society service" stems from the EU's Electronic Commerce Directive $(2000 / 31 / \mathrm{EC})$ and refers to applications provided over data networks.

${ }^{22}$ Commission of the European Communities, 2004.

${ }^{23}$ Or, if desired, even apply for the right to offer universal service under the USO category for a given jurisdiction. W hile no VOIP provider is li kely to apply for the role as universal service provider particularly in the infancy of VOIP - the Commission explicitly recognizes VOIP providers right to qualify for this role.
} 
Lastly, with respect to the critical issue of interconnection, the Commission's proposal emphasizes the right of all electronic communications providers - ECS and PATS - to negotiate interconnection agreements. As far a s IP-to-IP interconnection is concerned, peering arrangements among ISPs should suffice. With respect to interconnection between IP networks and the PSTN, however, intervention of NRAs may be necessary to ensure competitive access.

Given the overall benefits of ECS status, why would VOIP providers opt for the more stringent requirements of PATS? One reason is that PATS providers enjoy considerably more extensive rights in the area of numbering, particularly with respect to number portability and directory listings, and potentially with respect to geographic numbers. The Commission a dvocates making both geographic and non-geographic numbers available to any VOIP provider, be they ECS or PATS. Eu ropean consumers already have considerable experience with non-geographic numbers because these are used for wireless services. In fact, several industry analysts advocate using special VOIP prefixes to clearly distinguish VOIP from existing PSTN service. Conscious that a limitation to non-geographic numbers could disadvantage VOIP providers, however, the Commission calls on NRAs to make b oth types of numbers available. Yet th e EU regulatory framework restricts the right to port to existing numbers to PATS. Only a PATS provider could guarantee customers can retain their existing phone numbers despite a swit ch to VOIP.

One might think that the industry would be happy about the Commission's light-handed approach. Letting operators choose what category they want to fall under seems business-friendly. But this very much depends on where a company sees itself in the evolving market for VOIP services. I ndeed, initial resp onses to the Commission proposals suggest that the proposed freedom to choose is likely to come with significant restrictions.

\section{...but industry is split...}

Industry has been generally supportive of the Commission's proposals but various camps are taking different positions on specific issues. Indeed, it ap pears that rival industry camps are staking their claims on the issue of classification. A v ariety of stakeholders call for objective criteria to distinguish ECS and PATS providers. Former monopolists such as Germany's Deutsche Telekom or Spain's Telefónica, for example, are opposed to the notion that new VOIP providers may simply choose whether or not to comply with the PATS obligations that they themselves are subject to. T heir argument is that VOIP providers ought to be treated as PATS if they offer publicly available telephony services via ordinary phone numbers as a substitute to e xisting PSTN services. Telefó nica even wants NRAs to have the authority to change a VOIP provider's status from ECS to PATS if market analysis suggests such services are offered as full substitutes for circuitswitched telephony. In such cases, argue the incumbents, new VOIP entrants ought to comply with all aspects of existing regulation, including access to em ergency services and adherence to network security and quality-of-service standards. This position, interestingly, is also shared by several cable operators. 
Potential new entrants to the European market such as AT\&T, Vonage, or Pulver, in contrast, stress the importance of ensuring a level-playing field even for non-PATS providers of VOIP services. Since European broadband markets are still characterized by dominant former monopolists, new entrants are understandably concerned about adequate access to existing networks. Predictably, they demand full access to numbering resources - including geographic numbers - even for ECS providers. In line with Commission proposals, they stress that it would be sufficient for non-PATS VOIP providers to simply alert customers of the inherent limitation of cu rrent VOIP technology in the area of emergency call routing.

\section{....and the member states have their own ideas}

The European Commission may have an important role in interpreting EU regulation and proposing potentially necessary changes, but implementation and actual regulatory decision-making authority is exercised by the NRAs. S everal NRAs have begun their own VOIP consultations and a few have already handed down decisions. While regulators agree on some issues, different interpretations with potentially far-reaching implications loom.

Among the most important decisions has been the Finish regulator's authorization of TeliaSonera Finland's VOIP service designed specifically for business clients. TeliaSonera is the product of the merger between the Finnish and Swedish former monopolists and is the first PSTN incumbent to offer VOIP on a large scale in Europe. The company targeted its VOIP product to ex isting broadband business customers and deliberately marketed it as a substitute for PS TN telephony service. Accordingly, the Finnish Communications Regulatory Authority, Ficora, ruled that Teli aSonera would have to comply with the same regulation for this VO IP as for its conventional PSTN offerings. It officially classified the offering as a PATS service because it is first, available to the public; secondly, users originate and receive national and international calls and have access to emergency services; and thirdly, service is available through the Finnish numbering plan. ${ }^{24}$ Ficora requested that TeliaSonera develop and implement the ability to iden tify caller location for emergency services within six mo nths and meet other PATS obligations six months later.

The UK r egulator Ofcom, in co ntrast, is going down a different path. Rather th an classifying services as PATS when they meet the criteria contained in the EU regulatory framework and fairly strictly applied in the Finnish case, Ofcom proposes to assess broadly - and therefore almost by definition more subjectively - if a VOIP service is marketed as a replacement for existing PSTN service. Under this model, TeliaSonera's service might not have qualified as PATS and thus not been subject to the more stringent regulatory terms had the company not marketed its service deliberately as a PSTN substitute. Indeed, taking its clues from these signals, Vonage is deliberately refraining from marketing its service in the UK as a substitute for ordinary telephony. ${ }^{25}$ Ofcom has recently started a more comprehensive consultation on VOIP in which its simple focus on substitutability is likely to come under scrutiny. In the meantime, by introducing " 056 "

\footnotetext{
${ }^{24}$ Anderson, 2003a.

${ }^{25}$ Anderson, 2003b.
} 
as a special country-wide non-geographic prefix for VOIP services, the UK regulator is helping new entrants make the case that they are not offering a direct PSTN substitute as such a service would seek to employ existing geographic numbers - and thus freeing them from the more burdensome PATS obligation.

ART, the French regulator, appears to follow the Finnish interpretation of the EU framework. In fact, there is some indication the French might go as far as defining any publicly available service that provides direct, real time voice communication between fixed and/or mobile users as PATS, even though the Commission explicitly argues that such services could qualify as EC S and should be treated as such if the provider so chooses. ${ }^{26}$ Just like Ofcom and the German regulator RegTP, ART has recently launched a public consultation process that is likely to further clarify its position.

It is obvious that VOIP regulation in Europe is still very much in the making. The complicated division of labor between the European Commission as guardian of EU frameworks and the NRAs on the member state level that interpret and implement regulation does not make for straightforward policymaking. Any future VOIP regulation will evolve from the complex back and forth between European and national level policymaking.

As the administrative process unfolds, market players are positioning themselves to shape the classification of VOIP services according to their interests. Initial battle lines are becoming clear. There appears to be a clear distinction between current network owners and those hoping to roll out VOIP services over third-party broadband lines. Former monopolists have dominant positions in DSL markets and cable operators want to gradually introduce VOIP for their customers and are confident they can comply with PATS requirements, such as access to emergency services, wiretapping provision, and network integrity.

What incumbents want to avoid, however, is having to grant third-party VOIP providers that fall under the considerably less burdensome ECS regime access to their networks and customers. It is for this reason that they advocate objective criteria to distinguish PATS and ECS, quality-of-service obligations for both network owners and third-party application providers, and an obligation to ensure emergency service if VOIP is employed as a full-fledged PSTN substitute. In several member states, the call for objective distinctions appears to resonate with regulators.

In sum, recent European developments contain two obvious points of concern with potentially far-reaching implications. The first is that the European Commission's laudable goal of letting operators choose their regulatory classification is being undermined as regulators search for objective criteria in order to become more prescriptive. Secondly, regulators on the member state level are beginning to diverge in the way they define and apply objective criteria for classification of VOIP services under the EU framework. Put the two trends together and you have a considerable risk that dissimilar regulation across EU member states will fragment the European VOIP market.

\footnotetext{
${ }^{26}$ Anderson, 2003a.
} 


\section{The Politics of Regulatory Classification}

Both the EU and the United States have taken early steps to fit VOIP into existing regulatory classifications, a c ourse that is more advanced and seems somewhat more orderly in the European case. Yet, politics has inevitably intruded, with important implications for the future course of VOIP deployment.

\section{On jurisdiction}

The FCC's decision to settle jurisdiction first and substance later is, at best, curious. The European system offers prospective guidance on critical questions like interconnection, access to emer gency services, and network reliability. But the FCC has ousted state regulation without explaining what precisely is to replace it. Consider just one example. Suppose that a provider of broadband services in the United States were to deploy its own VOIP service and, simultaneously, either block access to competing VOIP applications, degrade the quality of their service or refuse to exchange traffic with them. With VOIP services within the exclusive jurisdiction of the federal government, what is the federal rule that either permits or limits such practices? At p resent, none exists. Yet, when, in February 2005, a VOIP provider asserted that a small telephone company was attempting to block its service, the FCC was quick to enter into a consent decree that guaranteed VOIP access. ${ }^{27}$ Even so, the FCC chose to act without establishing any general interconnection or open-access requirements. Indeed, the then-FCC Chair celebrated the agency's case-by-case approach, on the ground that "the surest way to preserve 'Net Freedom' is to handle these issues in an enforcement context where hypothetical worriers give way to c oncrete facts and - as we have shown today - real solutions." 28 This disavowal of a rules-based approach that provides clear guidance to industry players runs the risk of increasing inefficiency in the system unnecessarily. Ambiguity can add costs to the deployment of VOIP and thus can delay the deployment of new technologies.

The European approach also carries with it su bstantial risk. Because the European Commission retains the au thority within Europe to create h armonized regulatory frameworks and to coordinate implementation among the NRAs, the a llocation of regulatory authority is not quite as sharp as it first appears. Moreover, over the long-term, the allocation of responsibilities between the NRAs and the EC could fragment the market for VOIP services in Europe. The existence of separate national rules threatens to increase the cost of compliance to the detriment of the marketplace as a whole and to smaller nations in particular. Given the geography and business realities of Europe, there is no reason why a VOIP transmission from Paris to Brussels should be considered "international" while a transmission from New York to Los Angeles should be considered "domestic."

\footnotetext{
${ }^{27}$ See note 11 supra.

${ }^{28}$ See http://hraunfoss.fcc.gov/edocs public/attachmatch/DOC-257175A1.pdf, accessed 8 April 2005. Chairman Powell's espousal of "Net Freedom" refers, as his statement explains, to "a series of principles by which any company that intentionally breaks a co nsumer's connection to the Internet violates the openness that consumers have come to expect."
} 


\section{The struggle to classify}

The US system has one large disadvantage when compared to the EU approach. As a matter of history, the circuit-switched telephone network has been asked to support a number of social and political goals that are separate from the operation of the networks themselves. The most important is the universal service system; the most unjustifiable is the continuing application of a federal excise tax that was originally enacted in order to raise funds for the Spanish-American War. ${ }^{29}$ The revenue base for this system rests upon a simple proposition - that consumers have no close substitute for the use of the landbased, wireline, circuit-switched, telephone system. Indeed, to the extent that consumers substitute wireless service for traditi onal land-lines, taxing authorities have attempted to "equalize" the burden between the two services. ${ }^{30}$

In a world in which federal, state, and local tax revenues and support for universal service are network-centric, protection of that network from technological arbitrage is, at least in the short term, an ap pealing policy for any regulator. And this com bined legal/political dilemma may explain why the FCC has not proceeded more vigorously on the creation of an overarching framework in which companies can know in advance the re gulatory structure under which their VOIP activities will be measured. In fact, it has taken the FCC an extraordinarily long time to trave 1 even this far. In 1998, the FCC sent to

\footnotetext{
${ }^{29}$ In 2004, for example, the Maryland Public Service Commission identified the following taxes and fees on local telephone bills (See http://www.psc.state.md.us/psc/Info/brochures/telcharge.htm, accessed 8 April 2005):

- Federal Excise Tax of three percent;

- Federal Local Number Portability fee (\$0.23/line);

- Subscriber Line Charge, which supports the cost of local telephone service, with a cap of $\$ 5.61 /$ month for each primary line (and higher fees for non-primary lines);

- Federal Universal Service Fund in order to provide affordable telephone service for (1) those who live in areas where the cost of providing phone service is high, particularly rural areas; (2) those with low incomes; (3) schools and libraries; and (4) rural health care providers of $\$ 0.53 /$ line (and in addition to a similar universal-service fee that appears on the bill of long-distance carriers);

- 911 fee for the maintenance of emergency 911 service $(\$ 0.25 /$ month from the state plus a separate county fee);

- Dual Relay Service so that hearing and speech-impaired people would be able to use the telephone system (\$0.20/month);

- Gross Receipts Tax of 2.04 percent tax applied to all basic local service charges, all value added services, calls completed by the operator and message units;

- State Sales Tax of 5 percent on optional services (such as call waiting);

- Local Tax, varying by community (for example, 12 percent in the City of Baltimore).
}

The point is not to question the validity or wisdom of any of these fees, which spring from a variety of motives. The federal excise tax is, for example, entirely unrelated to the telephone system. Universal service funds serve public-policy goals that have been paramount in the United States since at least 1913. The Subscriber Line Charge is intended to allow the recovery of the costs of the network. And other fees are intended to recoup costs associated with the telephone networks that are carried out either by government directly, like emergency 911 service, or through the operations of the telephone networks, like dual relay service.

${ }^{30}$ For example, wireless customers in Maryland pay the same federal excise tax, federal USF fees, sales tax, local excise tax and 911 fees as on local wireline services. In addition, one county in Maryland has added a fee on wireless service to help fund local schools. See Mackey, 2004. 
Congress the so-called Stevens Report (named after the long-time Senator from Alaska Ted Stevens) that recognized the importance of offering a regulatory classification for VOIP services. Sadly, however, the report offered agonized ambiguity in place of clear guidance. It took six years before the FCC offered definitive (if limited) guidance in the pulver and AT\&T decisions. And, although the agency launched its rule-making process in early $2004,{ }^{31}$ the November 2004 Vonage Order went out of its way not to decide the question of regulatory classification. As we ha ve seen, even the FCC's most recent enforcement action fails to establish any general rule governing VOIP access to last-mile connectivity.

By contrast, the EU has taken a giant step forward by abolishing the "stovepipe" view of regulation that links regulation to underlying network technologies and that characterizes the 1996 US Tel ecom Act. This is a major step forward because it is, at bottom, accepting of tech nological change instead of being structurally opposed to it. The European approach thus (1) frees companies from seeking country-by-country authorization to operate; (2) establishes a neutral right of interconnection; (3) and establishes categories of communications services that are not grounded in network design. As discussed below, the categories themselves are not free from doubt, but the fundamental advantage here belongs to the European approach.

That said, the $\mathrm{p}$ roblem of regulatory definition $\mathrm{h}$ as not been totally eliminated by the European approach. The distinction in Euro pe between "Electronic Communications Service" and "Publicly Available Telecommunications Service" was established to enable providers to opt for lighter regulatory treatment and to match benefit and burden. But, in fact, as VOIP services have entered the marketplace, some incumbent European providers have pressed regulators to require VOIP providers to be regulated as PATS without regard to their wishes.

In this context, the question of "substitutability" has arisen as well and there are signs of emerging differences of approach among European regulators. The UK regulator Ofcom has begun to ask b roadly whether VOIP services are marketed as replacements for existing PSTN service rather than focusing more narrowly on the technological attributes of the service. Such an approach could be justified by service providers' own product marketing. To take a U.S example, the Vonage website prominently exclaims that "Using an existing high-speed Internet connection, Vonage technology enables anyone to make and receive phone calls - worldwide - with a touch-tone telephone."32

Ofcom's thinking and a focus on marketing statements means that a "common-sense" approach threatens to supplant regulatory classifications. Alt hough the US regulatory classifications are, in our view, fatally flawed, the trend in Europe towards classification applied regardless of a provider's wishes, may be no more sensible. Fo r example, concluding that VOIP providers must be required to meet quality-of-service requirements because they market a product that is "substitutable" for plain old telephone service would seem to miss the point, as some customers might specifically opt for VOIP to get

\footnotetext{
${ }^{31}$ In the Matter of IP-Enabled Services (Docket No. 04-36), released March 10, 2004.

32 See http://www.vonage.com/corporate/aboutus index.php (emphasis added), accessed 7 October 2004.
} 
cheaper service that they know comes with a lower quality. In other words, over-reliance on the notion of "substitutability" may actually lessen choice and product innovation in the marketplace. It is noteworthy that Ofcom's mere pondering of re gulation based "substitutability" is already showing effects in the marketplace. Vonage in the UK, in clear contrast to its above-cited US marketing, is deliberately marketing its service as a supplement to existing PSTN rather than a substitute, even though customers are of course free to cancel their ordinary PSTN service and rely just on Vonage. ${ }^{33}$

To put the issue of "substitutability" into broader perspective, consider just for a moment the manner in which it is applied in European anti-trust law. The European Commission has explained that the way to assess the scope of a product market is to examine whether a small, permanent increase in price for Product A would lead consumers to switch to Product B. Thus it explains:

\begin{abstract}
A practical example of this test can be provided by its application to a merger of, for instance, soft drink bottlers. An issue to examine in such a case would be to decide whether different flavours of soft drinks belong to the same market. I n practice, the question to address would be if consumers of flavour A would switch to other flavours when confronted with a permanent price increase of $5 \%$ to $10 \%$ for flavour A. If a sufficient number of consumers would switch to, say, flavour B, to such an extent that the price increase for flavour A would not be profitable due to the resulting loss of sales, then the market would comprise at least flavours A and B. The process would have to be extended in addition to other available flavours until a set of products is identified for which a price rise would not induce a sufficient substitution in demand. ${ }^{34}$
\end{abstract}

But here's the point. The com petition-policy analysis noted above does not require that product A and product B taste exactly the same - Product A might be cherry-flavored and product B might offer an o rangey bouquet. It's just that market analysis shows that existing cherry lovers might prefer to switch to orange rather than pay some amount more for cherry.

In the regulatory context, however, the analysis of "substitutability" serves a very different purpose, which is to threaten the erasure of product differences. Imagine if a cherry-flavored competitor asked a regulator to force the orange-flavored provider to change its flav or merely because the two drinks occupy the same product market. Just because products are similar, they do not have to be identical.

As the soda example shows, the application of a "substitutability" test for purposes of regulation may force VOIP to take on the characteristics of PSTN telephone service. So, for example, under the European regulatory scheme, a number is portable to a VO IP provider and a directory-assistance listing is a vailable only if it complies with all the requirements that define PATS service. The problem with this is that consumers may want the ability to choose just those characteristics that regulation would erase. They may want number portability to reduce switching costs but may be content with lower service quality because they are price sensitive or conclude that current quality

\footnotetext{
${ }^{33}$ Anderson, 2003b.

${ }^{34} \mathrm{See}$ http://europa.eu.int/comm/competition/antitrust/relevma_en.html, accessed 8 April 2005 . For a similar analysis in the US context see http://www.ftc.gov/bc/docs/horizmer.htm, accessed 8 April 2005.
} 
requirements are excessive. Or perhaps consumers think that the ability to be listed in a telephone directory is separate from obligations, as under the EU standards, of ensuring against network collapse.

\section{The purpose - and politics - of classification}

In the eyes of most regulators and industry observers, correctly categorizing VOIP provides a shortcut through regulatory uncertainty. Yet precisely this is the problem with classification. As p olicymakers almost reflexively ask how a new technology fits in to existing categories, the underlying political and social objectives of regulation can get lost. In the US for example, the distinction between basic and advanced services has its origins in the anti-trust battle against AT\&T in the 1970s and 1980s and is strongly characterized by public policy objectives of the time. The EU, in contrast, drew up its regulatory categories after the onset of $\mathrm{t}$ he Internet age and thus emphasized technological neutrality and future applications. Yet even here, regulation clearly reflects the political context in which it was formulated. In the European case, the overarching interest was to break the dominant position of former monopolists, particularly in the voice market, and to introduce greater competition into the broadband market. And yet, we have seen in the advocacy of those dominant players, a desire to use even the new regulatory categories in a way that will protect existing market share.

In short, while efforts to categorize new VOIP services according to existing regulation have taken center stage, the growing disjuncture between the political objectives reflected in these categories and future policy priorities could break open the debate and throw VOIP into even greater regulatory limbo.

We tend to think of telephone service as both network-centric and composing a particular bundle of product attributes. Ev en if, as Europe has done, regulation becomes technologically-neutral, the question remains: is government assuming a set of product attributes for voice service that is not necessary and that, therefore, acts as an impediment to consumer choice and VOIP adoption? It is very important for regulators not to fall into the trap of erecting inadvertent barriers to acceptance or entry by failing to ask whether all the things that we have tra ditionally considered to be a part of telephone service are actually required in a world of competing kinds of voice service.

The question is particularly important for an emergent technology. The best path for new technologies entering the marketplace may be to offer an alternative - not a direct substitution - for an existing product or service. ${ }^{35}$ But regulation that forces VOIP to act just like an incumbent's service can threaten its ability to differentiate and employ any particular advantages it enjoys. Indeed, the course of emerging technologies like instant messaging and email might have been very different if they had been viewed, at the outset, as having the potential to compete directly with existing, but seemingly distinct, communications capabilities such as traditional voice service.

\footnotetext{
${ }^{35}$ In fact, as Clayton Christensen has powerfully shown, most "disruptive technologies" develop along this trajectory. Precisely because they are sufficiently similar to be adopted as substitutes but different enough to offer new features, these technologies have such a dramatic impact. See Christensen, 2000.
} 


\section{CONCLUSION}

Propelled by physics, the future of VOIP may be shaped more by politics. As we have seen, the different approaches of the EU and the US have not constructed any sort of "neutral" zone in which issues of VOIP deployment can be adjudged only on their technical merits. In the US the history of linking social and economic policies to a network-centric view of the world has caused inevitable confusion as services become increasingly application-centric. In the EU, the implemen tation of forward-looking, technologically-neutral classifications has not rendered the application of regulatory discretion immune from political advocacy by dominant carriers.

The EU approach - de-linking social and economic issues from the operations of particular networks - is clearly preferable. In such a wor ld, the merits of so cial and economic policies will be more visible to the body politic simply because they cannot be hidden within the opaque operation of incumbent network providers. And transparency will allow such policies as universal service to be more successful because they can be boosted by competition, instead of depending on the maintenance of past market structures.

At the same time, and to the extent that regulators on both sides of the Atlantic begin to ask whether VOIP services are "substitutes" for existing services, it is very important not to assume that con sumers will $\mathrm{w}$ ant what the $\mathrm{y}$ have always have received. There is a natural tendency to assume that "telephony" composes a specified set of product attributes but that assumption must be rigorously examined and re-examined as technology and consumer expectations evolve. The risk, of course, is that new forms of stovepipes will emerge to replace the old ones.

VOIP is an application newly-available for mass audiences and there is likely to be great dynamic change in the markets as it is adopted. We certainly do not yet know whether copper-based circuit networks will continue to be used, how nomadic the use of VOIP devices will become, or the extent to which consumers and businesses will fully adopt the ability to integrate voice, video, and data services.

Governments can take two attitudes towards this uncertainty. They can move cautiously, trying to exempt VOIP from previous regulation on the ground that it is a nascent technology or, even when they rule more broadly, continue to leave great uncertainty in their wake. That $\mathrm{h}$ as been the attit ude of the United States government since at least 1998. The failure to act decisively does, of course, guard against potential error.

We believe, however, that the deadweight costs of such recalcitrance outweigh its benefits. Governments in both Europe and the United States should move aggressively at the federal - or in the European case EU - level to establish the rules of the road so that innovators understand their environment and so that competition is driven by underlying value rather than transient arbitrage or regulatory distinctions. 
In that case, how can they learn? First, through international consultation. Europe and the United States (much less the rest of the world, including the nations of Asia that lead the globe in broadband deployment) need not adopt the identical rules. They can leave room for experimentation. For example, the approach to emergency services need not be identical - perhaps there is a requirement for governmental mandate, perhaps for voluntary (but ubiquitous) industry action, perhaps only for government-mandated consumer notice. At the same time, some core principles - like access to markets - will probably require harmonization, as VOIP services swap across borders.

Second, by understanding the limits of governmental wisdom. In the current climate, inaction is no $t$ the best way to express caution (because it leav es the helter-skelter structure of outmoded laws in place). It would be better for governments to express limits of omniscience by placing time limits on broad rules, in order to assure that they will be reviewed in five or seven or ten years, rather than eschewing such guidance altogether. Governments should be forced to re-learn the marketplace and the trajectory of technology so that they can clearly see which of their prior assumptions have proven to be false and which aspects of the current condition they prior rules failed to anticipate. In the world of technology, in particular, it is better to inject some minor uncertainty about the nature of governmental action as it may exist a half-decade hence rather than to fall victim to the dead-weight burden of outmoded reasoning.

Third, and perhaps most importantly, governments need to understand how and why new technologies emerge and why it is im portant not to stifle them by using approaches designed in different times for different purposes. Evolution is a natural course of market dynamics and differentiation is at the core of evolutionary progress. Thus, governments must be careful not to take actions that inadvertently limit technology and, in the process, constrain their essential, innovative attributes.

VOIP provides a great opportunity to put this fundamental insight into practice. The technology is certain to transform the telecommunications industry. If this prompted governments to re-think and re-examine its own role in the process, the technology has the potential to radically transform the field of telecommunications regulation as well. Were this to happen, VOIP would indeed signal an entirely new era on all fronts. 


\section{REFERENCES}

Anderson, T. (2003a, 2 December). EU member states gear up to regulate voice over IP. Telecom Markets.

Anderson, T. (2003b, 23 Se ptember). Vonage lawyers testing Euro-VOIP conditions before '04 launches. Telecom Markets.

Bach, D. (2000). International Cooperation and the Logic of Networks: Europe and the Global System of Mobile Communications (GSM). BRIE Working Paper \#139.

Bar, F. (2001). The Construction of Marketplace Architecture. In The BRIE-IGCC Economy Project (Ed.), Tracking a Transformation: E-commerce and competition in industries (pp. 27-50). Washington, DC: Brookings Press.

Christensen, C. M. (2000). The Innovator's Dilemma. New York: Harper Business.

Clark, R. (2004, February). Voice over internet protocol. Telecom Asia.

Cohen, S. S., DeLong, J. B., \& Zysman, J. (2000). Tools for Thought: What is New and Important about the "E-conomy". Berkeley: BRIE, University of California, Berkeley.

Commission of the European Communities. (2004). The treatment of Voice over Internet Protocol (VOIP) under the EU Regulatory Framework: An Information and Consultation Document. Brussels: DG InfoSoc.

ENUM.org.ENUM - Frequently Asked Questions. Retrieved 8 A pril, 2005, from http://www.enum.org/information/files/enum faq.pdf

Isenberg, D. (1997). Rise of the Stupid Network. Retrieved 8 A pril, 2005, from http://www.hyperorg.com/misc/stupidnet.html

Japan's VOIP Experience Could Preview Things To Come In America. (2003, 8 October). Telecom Policy Report.

Kerner, S. M. (2004, 7 October). VOIP To Hit 12.1 Million Households By 2009. ClickZ News.

Le Maestre, R. (2003, 2 December). Europe's VOIP Scene Is Hot. Light Reading.

Mackey, S. (2004, 19 July). The Excessive States and Local Tax Burden on Wireless Telecommunications Service. State Tax Notes.

Sallet, J. (2003). Just how open must a n open network be for an open network to be labeled "open"? First Monday, 8(3).

Thatcher, M. (1997). The Development of European Regulatory Frameworks: The Expansion of European Community Policy-Making in Te lecommunications. In S. 
Stavridis (Ed.), New Challenges to the European Union: Policies and Policy-Making. Brookfield: Dartmouth Publishing Company.

Thatcher, M. (1999). The Politics of Telecommunications. National Institutions, Convergence, and Change. Oxford: Oxford University Press.

Thatcher, M. (2002). The Relationship between National and European Regulation in Telecommunications. In J. Jordana (Ed.), Telecommunications and the New Information Society in Europe. Cheltenham: Edward Elgar. 
NOTAS 